\title{
The cultivation study of physical education to college students' self-consciousness
}

\author{
Jian $\mathrm{Li}^{1, \mathrm{a}}$ \\ ${ }^{1}$ Shaanxi University Of Science \& Technology, Xi'an, Shaanxi Province, China \\ alijiantiyu@sust.edu.cn
}

Keywords:Physical education, College students, Self-consciousness, Development

\begin{abstract}
Sports education is to train students in colleges and universities student one of the important composition of self-consciousness, through physical education to the cultivation of the students' self-consciousness is the most effective way, in the sports practice can greatly stimulate students' interest, improve students self-aware of subtle effect. To become qualified successors of socialism, in addition to the professional knowledge of science and ambitious, strong body is the premise of realization of the value of life, on the basis of physical education, all-round development of students' physique and law, is to complete the teaching task must conscientiously implement the higher requirements.
\end{abstract}

\section{Introduction}

Sports education is an important means of promoting students physical and mental health, in today's competitive environment, cultural education is necessary, but the role of physical education is also very important, physical education, with its inherent openness, practicality, etc will be a very good to the cultivation of the students' self-consciousness in the root [1]. Through physical education in a strong student body at the same time, the basic quality education is blended in among them, improve the physical fitness and improve the student's quality education, you'll learn is the new orientation of sports education career.

\section{The necessity of self-awareness training of students in colleges and universities sports education}

The cultivation of basic quality goes through in physical education, this is the new requirement of the new age of sports educators. Should first change is the idea of people in traditional physical education, physical education is no longer crazy jumping from the free surface activity, but in order to promote students' physical development, strengthen physical health as the goal, to strengthen a sense of sports culture inheritance, attaches great importance to the sports psychological quality training of new ideas, the long-term practice has proved that the body is the most honest language, through various sports activities can true reflect the students' thought and behavior, the students' quality education has a great role in promoting, put on the cultivation of students' basic quality, not only make the students master the basic knowledge of the basic methods of fitness and body function, but also in practice for students of psychological health, team cooperation consciousness, ideology and moral character education, creative thinking, etc. all have certain effect.

For students is about to become social builders, physical education not only has the knowledge to teach students sports skills, enhanced physique, assuming the task of cultivating students' self-consciousness. With the constant progress of science and technology, the rapid development of society, the life of people pressure is, the more heavy, to survive in such an environment, not only requires students to master advanced knowledge of science, modern science and technology, have strong physique, healthy psychology and sound personality [1]. In order to adapt to the needs of society, colleges and universities to cultivate students to have the courage to struggle, dare to hit the spirit of quality, it has to do with physical education, in the various sports competitions, students strive to catching up, refused to give in the spirit of all is to satisfy the needs of the future social life. 


\section{In colleges and universities sports education to culture the students' self-consciousness}

Colleges and universities sports education by promoting the process of the development of the students' ability, make students ability in many aspects and satisfaction. The new sports education idea is not only strengthen the exercise of students' physical quality, but also the cultivation of the embodied self-consciousness education, expand the connotation of sports education to cultivate students ability to adapt to social development, using the special physical education effect makes students body and mind, and improve quality and other aspects are so as to cultivate qualified successors and builders of socialism [2]. Advocating quality-oriented education, the student's quality education throughout the teaching of the school education is the inevitable path of new historical period, physical education is the important part in the school education teaching, and is also the basis of cultivating students' quality education link, therefore, the physical education of university library in the quality-oriented education.

Strengthen the sports cultural quality consciousness. Teachers in classroom practice, should pay attention to construction of literacy skills, as a way of literacy training. In outdoor in the class, for example: physical education teachers students can be divided into equal groups, small group activities and make students separately, cooperate, let the student understand the team consciousness, and improve students' consciousness of unity and cooperation, make students understand feeling sports cultural literacy in the practical courses [2]. Thus, through the initiative of students, build the scope of cultural quality, leading to the other students and teachers in which only play a role in promoting, such construction way in sports in the construction of cultural literacy, have higher practical value. In colleges and universities sports resources are very abundant. The teacher may use it as a strengthening sports student's cultural quality of backup resources. For example, teachers play the video data of each sports event in our country, through physical there, arouse the students' humanities accomplishment, inner focus to watch sports athletes in our country sports performance, sports teachers can tell students, we are on the sports ground movements, not only on behalf of individuals, but also on behalf of the class, students, and even on a bigger stadium, will mean big meaning, sports video data provided by physical education teachers and the teacher to explain, realize the significance of cultural quality. So, facilitate gave birth to a better understanding of sports, better realize the sports spirit, better sports life, better to participate in sports activities, to the spirit of sportsmanship.

Cultivate the students' sports consciousness. School sports teaching should make students correctly understand their own thoughts and behavior, pay attention to cultivate the students' self-consciousness of sports, this is an important content of developing students' consciousness of lifetime sports. Self-consciousness of sports, is based on their needs, according to their interests and hobbies, consciously take exercise, know their state of physiological, psychological characteristics, sports technology and its relationship with others [3]. All in all, sports consciousness is for the understanding of the state of mind. Students in physical education teaching, is a kind of have a clear purpose, a variety of difficulties and obstacles, need will participate in the action, so teachers should enhance the understanding of the students, to guide the consciousness activity. Cultivate the students' will and support their positive understanding, this can make the consciousness of students have a positive impact. Is an extremely important aspect of training students to consciously to overcome difficulties. Consciousness cultivation process in fact is also strong command of mobilization, process. Therefore, quality education is to cultivate the ability of self will.

Change student's attitude toward sports. So-called change students attitude, is the teacher in the teaching process, through a variety of effective ways and methods, shift students various incorrect attitude towards sports, make sports students conscious action and an important content in the future life. Now college students is generally accepted that has nothing to do with the course of university physical education curriculum, so do not take the sports, ignore the importance of sports, the lack of correct thinking and understanding, there are even tired of thinking [3]. In the sports teaching, teachers should use various effective ways and methods to change the wrong understanding of sports, change student's thought, to improve students' understanding of sports, to cultivate and arouse the students' enthusiasm for sports, make sports students conscious action and an important part of life in 
the future, through sports science study goal and the good learning motivation, learning attitude, so as to set up the lifelong sports consciousness.

Train their consciousness of competition. Competition is the most prominent characteristics, sports competition and competitive spirit is the distinctive features of primary and middle school students [4]. Sports games, contests, sports competition, various tests and scores are to cultivate students' competitive consciousness created plenty of opportunities and good conditions. To mobilize the students too actively into the competition and self ability show activities, to cultivate students' competitive consciousness, improve their competitive ability.

The development of the personality of students. Personality is a person to the objective reality, solid attitude as well as the corresponding habitual behavior characteristics in heart. Different sports, to participate in personality characteristics have different requirements, so the participants through different activities of the project, to develop their good character, character weakness [4]. Take part in football sports, for example, it is a collective project, asked participants with a quick wit, dare to dare to spell, calm, together with a good attitude and psychological quality, often take part in the sports can cultivate students' good personality, especially for those who are introverted, withdrawn, weak and indecisive students can overcome its character weakness, gradually form a bright and cheerful disposition, brave, tenacious character.

To the cultivation of character. In the sports teaching, training and competition, participants must be conducted before difficult self-discipline, mobilization, hint, commands, and experience, in a timely manner to overcome a lots of difficulties and obstacles [1]. Every step forward made by the movement to the will of great effort. The victory also often depends on the efforts of "stick". For now is only children more primary and middle school students, only to "hold on" long-term efforts, more benefits will quality cultivation.

\section{Colleges and universities sports education to train students' self-consciousness}

The sports education itself is to make students set up healthy psychological quality. Among various kinds of sports activities, students actively participate in the show ego, is beneficial to cultivate the students' self-confidence, enhance the affirmation of the self. In addition to a strong body, the students can also make its own body workout, establish a good personal image, to show more positive mental outlook. Physical activities can let students to release pressure, relieve mood, will yu gas vent in the heart, learn to calm about things, and from time to time, athletic contest, is to let students know how to face the winning or losing on the field, to learn on their own struggle to win and enjoy after efforts to bring the joy of; Or behind the others, correct attitude to continue the next refueling [2]. This is what the future meet success or failure in the society to have psychological quality, only have the courage to accept the challenge to confront the difficulties to achieve the final success.

Physical education is a cultural quality and service, strengthen the student's thought moral education in practice. In various sports activities, through the parade, gymnastics to strengthen students' organizational discipline, pay attention to serious, show vibrant spirit of students; Through the long sprint training students' perseverance, courage of spirit; By jumping growth challenge students overcome difficulties of courage; Through team sports training students' sense of team spirit and collaboration; Through gymnastics dance exercise the student physique, edify sentiment cultivate positive, cheerful personality [5]. Physical education is the most important thing is to cultivate the students' desire to do better, encourage students to try in the competition, continuously enterprising, innovation, make a man of integrity with its own actual ability to overcome each other. In the face of the battle to have the right attitude, you win some common, constantly in the success and failure experience, cultivate correct moral values.

Strengthen self-awareness, mobilize initiative.In the sports lesson, govern self-consciousness of students body movement, saturated with social, political, economic, cultural, moral and the influence of factors such as the national spirit. Physical education teachers should have the destination to cultivate their sense of self, with noble social factors controlling students sports drive, to create ideal personality cultivation and development of sports environment, in the teaching, to clear the students' 
subject status, inspire their self activities of the initiative as far as possible, and give full trust and respect, to provide more freedom, take part in physical activities become students passive to active pursuit [5]. Students sense of honor and competitive, game teaching can be more organization, increase in severity and interest, according to the students' gender, physical fitness, skills, technology and other differences, to adopt the game, let, let the game from such, stimulate the enthusiasm, play to their initiative.

Consciously into the psychological training. In sports teaching, teachers should consciously and purposefully to the student's psychological influence, make its physical and mental state can withstand victory, setbacks, and repeatedly different tolerances in prosperity and adversity, to achieve the degree of self-regulation [1]. As for students of poor physique, technique, to encourage and help them build up confidence, can't often called out in the wrong model to perform; To approach them with the initiative enthusiasm, especially when learning new movements patience guidance, patience guidance when necessary, decrease the requirements when necessary, to let the students taste the joy of their progress, make them have confidence to learn new technology.

To create a good physical environment. In sports teaching planning and implementation, to establish a good relationship between teachers and students, should choose vivid interesting, conform to the teenagers physiological and psychological characteristics of the teaching material, develop the students' moral sense, aesthetic feeling and sense of responsibility, guides the student to sports training honed his character. Such as, can according to the characteristics of the girl's pursuit for beauty strongly, such as choice of rhythmic gymnastics, dance, aerobics teaching material, let them in with a music gymnastics practice room. At the same time, to a reasonable choice is advantageous to the development of female physiological function, improve learning fun and good initiative.

Grouping teaching according to students interested in choice. Interest is influence teaching effect factors of effect extremely obvious psychological factor, because the student interest, often to the same teaching material, the same content have different interests, the teaching result is very different. In order to guarantee the teaching quality and cultivate the student individuality, teachers can choose grouping teaching according to students interested in. Due to the small group of students is like a sport and voluntary learning, learning motivation must be positive. Such organization arrangement, make students not only fully, and easy to complete the teaching task, can make the students enjoy sport, enjoy, the mood will be very cheerful.

Innovating the teaching methods and teaching content. We want to get rid of the traditional sports teaching mode, make sports from life in happy learning and physical exercise, sports derive great pleasure out of. Often used in sports teaching of six kinds of methods, namely: listening to think, learn and think, practice and taste, talking and demonstration, do discussion, while thinking while induction. Let sports born in real live, move to pleasure, do the happy study master, make the best teaching effect, the teaching efficiency to the fullest [4]. Contemporary education, seriously looking for a way, is more important than the transfer and storage of knowledge. Sports is a process of energy consumption, and also ways to exercise the body, after the movement of the restoration and maintenance is worth us to learn, to achieve the best effect. Cultivating sports learning scientific physical training methods, sports after self observation and analysis, the ability of self assessment is the main content of the sports ability of ascension. On the choice of teaching contents in physical education teachers should adapt to the characteristics of sports physiology, psychology, knowledge level, increase the sports knowledge, pay attention to sports, the application of knowledge, and at the same time increase the literacy class of sports theory class, courses in related sports theory of knowledge, increase the basic knowledge of sports. In response to the call of lifetime sports, sports theory course in time to learn the latest sports content, reasonable sports participation and active to do your own body to assess and improve the theoretical knowledge. Outdoor sports technology learning should be combined theory and technology, not only to practice during learning technology to scientific, exercise also teaching students to master the skills and techniques.

Stimulates the student to study the sports cultural literacy. First, the physical education teachers should cultivate students' interest, interest is the best teacher. Actively observe the advantages of sports life, born on sports encouragement, praise for their progress, born to sports to 
create more chances of success [5]. Born in physical education, sports, every sports activities, can make the sports success experience. Second, the physical education teachers to strengthen management, to oneself for the students to adopt a reasonable management mode, an orderly group, as a member will have a sense of pride. Third, improve teachers' cultural quality, physical education teachers in colleges and universities is the main effect of physical exercise habit, is sports directly imitate, the exemplary role and influence of precept is an important image of PE teachers play a teacher by worthy example. Teachers should also teach students what modern society need to raise the talented person, lets the student earlier to make life planning, determine the goals.

\section{Summary}

Through physical education for students in the cultivation of the sense of self is the most effective way of physical education in a strong student body at the same time, the basic quality education is blended in among them, you can implement the cultivation of student's self-consciousness. In today's competitive environment, not only requires students to master advanced knowledge of science, modern science and technology, have strong physical quality, healthy psychology and sound personality. Using the special physical education effect makes students and other aspects of body and mind quality and improve all of that is more adapt to the needs of the future society.

\section{References}

[1] J.X. Song, Concerning the future of college sports thought transformation, modern intelligence, 2008, vol.12, pp-57-61.

[2] D.X. Qiao, How to cultivate students' innovative consciousness and innovative ability, Journal of Harbin institute, 2002, vol.10, pp.59- 63.

[3] S.T. Yang, Theory of sports colleges and universities on the cultivation of students' innovative quality, Sports science, 2003, vol.1, pp.17-20.

[4] X.J. Chen, Talking about the cultivation of sports college students' innovation consciousnes, Wuhan sports college journal, 2003, vol.5, pp.20-25.

[4] G.W. Liu, Knowledge economy of the innovation education, Journal of Harbin institute, 2002, vol.4, pp.2-8.

[5] Y.P. Wu, The knowledge economy era and the reform of institutions of higher learning education, School sports journals in China, 2002, vol.3, pp.29-31. 